\title{
Approximation and Controller Design for Fractional Order System
}

\author{
Shiv Shankar Kumar ${ }^{1}$, Awadhesh Kumar ${ }^{2}$ \\ MMMUT, Gorkhpur ${ }^{1,2}$
}

\begin{abstract}
The analysis of fractional system model is very complicated and tedious. From literature it has been clear that for study of fractional system one should have very deep knowledge about this system. To overcome this problem fractional system approximation techniques are developed. In this chapter Oustaloup's approximation method has been used for approximating the fractional system. The approximated model of fractional system will be of very large order and again new problem arises that the controller designed for approximated model will be of very higher order. Hence controller designed will be very costly and larger in size. Thus Model Order Reduction Technique has been used to overcome from this problem. Using MOR the order of approximated model should be reduced and then reduced order controller has been designed for fractional order system.
\end{abstract}

Keywords: Fractional Syatem, MOR; Oustaloup's technique; Hankelnorm approximation; Fractional PID Controller.

\section{INTRODUCTION}

Oustaloup's technique a recursive filter is give a very good approximation of fractional system fundamentals $s^{\gamma}$ chose frequency band (Oustaloup et al. 2000). In a individual frequency range $\left(\omega_{\mathrm{b}}, \omega_{\mathrm{h}}\right)$ and order N. Oustaloup's technique is recursive filter used for $\mathrm{s}^{\gamma}$ for $0<\gamma<1$. is given

$$
\begin{aligned}
& \mathrm{G}_{\mathrm{g}}(\mathrm{s})=\mathrm{s}^{\gamma}, \gamma \in \mathbb{R}^{+} \\
& (\mathrm{s})=\mathrm{K} \prod_{\mathrm{k}=-\mathrm{N}}^{\mathrm{N}} \frac{\mathrm{s}+\omega_{\mathrm{k}}^{\prime}}{\mathrm{s}+\omega_{\mathrm{k}}} \prod_{\mathrm{k}=-\mathrm{N}}^{\mathrm{N}} \frac{\mathrm{s}+\omega_{\mathrm{k}}^{\prime}}{\mathrm{s}+\omega_{\mathrm{k}}}
\end{aligned}
$$

where, $\omega_{\mathrm{k}}^{\prime}, \omega_{\mathrm{k}}$ and Kis obtained since

$$
\begin{aligned}
& \omega_{\mathrm{k}}^{\prime}=\omega_{\mathrm{b}}\left(\frac{\omega_{\mathrm{h}}}{\omega_{\mathrm{b}}}\right)^{\frac{\mathrm{k}+\mathrm{N}+\frac{1}{2}(1-\gamma)}{2 \mathrm{~N}+1}} \\
& \omega_{\mathrm{k}}=\left(\frac{\omega_{\mathrm{h}}}{\omega_{\mathrm{b}}}\right)^{\frac{\mathrm{k}+\mathrm{N}+\frac{1}{2}(1+\gamma)}{2 \mathrm{~N}+1}} \\
& \mathrm{~K}=\omega_{\mathrm{h}}^{\gamma}
\end{aligned}
$$

A refined Oustaloup's technique is given by [27]

$$
\mathrm{s}^{\alpha} \approx\left(\frac{\mathrm{d} \omega_{\mathrm{h}}}{\mathrm{b}}\right)^{\alpha}\left(\frac{\mathrm{ds}{ }^{2}+\mathrm{b} \omega_{\mathrm{h}} \mathrm{s}}{\mathrm{d}(1-\alpha) \mathrm{s}^{2}+\mathrm{b} \omega_{\mathrm{h}} \mathrm{s}+\mathrm{d} \alpha}\right) \mathrm{G}_{\mathrm{p}}
$$

$\mathrm{G}_{\mathrm{p}}, \omega_{\mathrm{k}}, \omega_{\mathrm{k}}^{\prime}$ also computed as follows

$$
\begin{aligned}
& G_{p}=\prod_{k=-N}^{N} \frac{s+\omega_{k}^{\prime}}{s+\omega_{k}} \\
& \omega_{k}=\left(\frac{b \omega_{h}}{d}\right)^{\frac{\alpha+2 k}{2 N+1}} \\
& \omega_{k}^{\prime}=\left(\frac{d \omega_{b}}{b}\right)^{\frac{\alpha-2 k}{2 N+1}}
\end{aligned}
$$

where, $\omega_{\mathrm{b}}$ is smaller value of frequency and $\omega_{\mathrm{h}}$ is bigger value of frequency. For low-order approximations shorter value of $\mathrm{N}$ should be selected which are trouble-free in nature but ripples are present in bode plot. For eliminate these ripples, $\mathrm{N}$ has to be enlarged. Higher value of $\mathrm{N}$ makes the calculation heavier. 


\section{MOR USING HANKEL-NORM APPROXIMATION}

Model order reduction is a tool used for reducing order of higher order system for providing easiness in analysis and simulation. Here one of MOR technique named Hankel-norm approximate on has been used.

The Hankel Norm approximation and Hankel Operator Given a state-space Hankel norm of model $G_{n h}=\left(A^{\prime}, B^{\prime}, C^{\prime}, D^{\prime}\right)$ is defined by the $H_{\infty}$

$$
\left\|G_{h}^{\prime}\right\|_{H}^{2}=\sup _{u \in L_{2(\infty, 0]}} \frac{\int_{0}^{\infty} y(t)^{2} d t}{\int_{-\infty}^{0} u_{(t)^{2} d t^{\prime}}^{\prime}} \quad \quad y^{\prime}(t)=\int_{-\infty}^{0} C^{\prime} e^{A^{\prime}(t-s)} B^{\prime} u^{\prime}(s) d s
$$

The Hankel energy is transferred from past inputs into future outputs during the system $\mathrm{G}_{\mathrm{h}}{ }_{\mathrm{h}}$ we discussed shown

$$
\left\|G_{h}^{\prime}\right\|_{H}=\sqrt{\lambda_{\max }(P Q)}=\sigma_{1}
$$

The Hankel operator $\Gamma_{G^{\prime}}$ of the system $G_{h}^{\prime}$ as:

$$
\begin{gathered}
\Gamma_{G^{\prime}}: L_{2}^{\prime}(0, \infty]: \\
\left(\Gamma_{G^{\prime}} u^{\prime}\right)(t)=\int_{-\infty}^{0} C^{\prime} \mathrm{e}^{A^{\prime}(t-s)} B^{\prime} u^{\prime}(s) d s, \quad t>0 .
\end{gathered}
$$

Hankel operator $\Gamma_{G}$ is equal to the Hankel norm system of $\left.G_{h}^{\prime} \cdot|| \Gamma_{G^{\prime}}\left\|=|| G_{h}^{\prime}\right\|\right|_{H}$

A good properties of Hankel operator $\Gamma_{G^{\prime}}$ has finite rank, by the rank equal to the minimum number realized the inputoutput systemG $\mathrm{h}_{\mathrm{h}}$,

$$
\operatorname{Rank} \Gamma_{\mathrm{G}^{\prime}}=\mathrm{n}
$$

We make the SVD of the $\Gamma_{\mathrm{G}}$, by the dyadic development as follows

$$
\left(\Gamma_{G^{\prime}} u^{\prime}\right)(t)=\sum_{i=1}^{n} \sigma_{i} u_{i}^{\prime}(t)\left(v_{`_{i}}, u^{\prime}\right)_{L_{2}(-\infty, 0]} \text {, }
$$

$\sigma_{\mathrm{i}}$ is the Hankel singular value of the system $\mathrm{G}_{\mathrm{h}}^{\prime}$, and singular vector is

$$
\mathrm{v}_{\mathrm{i}} \in \mathrm{L}_{2}(-\infty, 0], \mathrm{u}_{\mathrm{i}} \in \mathrm{L}_{2}[0, \infty) \text {. }
$$

Possible the one more think is more natural of believe in the operator $\mathrm{G}_{\mathrm{h}}$ is

$$
\begin{aligned}
& \mathrm{G}_{\mathrm{h}}^{\prime}: \mathrm{L}_{2}(-\infty, \infty) \rightarrow \mathrm{L}_{2}(-\infty, \infty) \\
& \left(\Gamma_{\mathrm{G}^{\prime} \mathrm{u}}\right)(\mathrm{t})=\int_{-\infty}^{\mathrm{t}} \mathrm{C}^{\prime} \mathrm{e}^{\mathrm{A}^{\prime}(\mathrm{t}-\mathrm{s})} \mathrm{B}^{\prime} \mathrm{u}^{\prime}(\mathrm{s}) \mathrm{ds}+\mathrm{D}^{\prime} \mathrm{u}^{\prime}(\mathrm{t}) .
\end{aligned}
$$

The operator normally not of finite rank and it have been no finite development in the equation further analysis is difficult. For the SVD of $\Gamma_{\mathrm{G}}$, by the apply Schmidt-Mirsky Theorem for establish equation given by:

$$
\left\|\Gamma_{\mathrm{G}^{\prime}}-\Gamma_{\mathrm{G}_{\mathrm{r}}^{\prime}}\right\|=\left\|\mathrm{G}_{\mathrm{h}}^{\prime}-\mathrm{G}_{\mathrm{r}}^{\prime}\right\|_{\mathrm{H}} \geq \sigma_{\mathrm{r}+1}
$$

Hankel norm is explanation the $G_{r}^{\prime}$ of order $r$. Denoted of the hankel norm plain that $\left\|G_{h}^{\prime}\right\|_{H} \leq\left\|G_{h}^{\prime}\right\|_{\infty}$ designed for all $G_{h} \in H_{\infty}$.

\section{STATE SPACE FORMULAS USED FOR BUILDING Q}

State space techniques of the calculation an optimal Hakel norm approximation Q .

Assume the system $G_{h}^{\prime}=\left(A^{\prime}, B^{\prime}, C^{\prime}, D^{\prime}\right) \in H_{\infty}$ is order $\mathrm{n}$, as well as square $(\mathrm{m}=\mathrm{p})$. The technique used for non-square method is a more complex linear robust control.

Suppose that the consciousness of the system $G_{h}$ is the Gramians obtain this form

$$
\begin{aligned}
& P=\left[\begin{array}{cc}
P_{1} & 0 \\
0 & \sigma_{r+1} I_{l}
\end{array}\right] \\
& Q=\left[\begin{array}{cc}
Q_{1} & 0 \\
0 & \sigma_{r+1} I_{l}
\end{array}\right]
\end{aligned}
$$

Where 1 is multiplicity for the singular value $\sigma_{r+1}$. One be able to decide a permuted objective realization of $G_{h}^{\prime}$, and P, Q, of the state-space system of $G_{h}^{\prime}$.

$$
A^{\prime}=\left[\begin{array}{ll}
A_{11}^{\prime} & A_{12}^{\prime} \\
A_{21}^{\prime} & A_{22}^{\prime}
\end{array}\right]
$$




$$
\begin{aligned}
& B^{\prime}=\left[\begin{array}{l}
B_{1}^{\prime} \\
B_{2}^{\prime}
\end{array}\right] \\
& C^{\prime}=\left[\begin{array}{ll}
C_{1}^{\prime} & C_{2}^{\prime}
\end{array}\right] \\
& D^{\prime}=D_{1}^{\prime}
\end{aligned}
$$

The unitary matrix $U \in \mathbb{R}^{p \times m}$, and $U^{T} U=I$, i.e.

$$
B_{2}=-C_{2}^{\top T} U
$$

Since the follow as this form

$$
E_{0}=Q_{1} P_{1}-\sigma_{r+1}^{2} I
$$

A define is Hankel norm approximation $\mathrm{Q}$ is explain of this form

$$
\begin{aligned}
& \overline{A^{\prime}}=E_{1}^{-1}\left(\sigma_{r+1}^{2} A_{11}^{\top T}+Q_{1} A_{11}^{\prime} P_{1}-\sigma_{r+1} C_{1}^{T} U^{\prime} B_{1}^{\top T}\right) \\
& \overline{B^{\prime}}=E_{1}^{-1}\left(Q_{1} B_{1}^{\prime}+\sigma_{r+1} C_{1}^{\prime T} U^{\prime}\right) \\
& \overline{C^{\prime}}=C_{1}^{\prime} P_{1}+\sigma_{r+1} U B_{1}^{\prime T} \\
& \overline{B^{\prime}}=D^{`}-\sigma_{r+1} U
\end{aligned}
$$

The transfer function $Q(s)=\left(\overline{A^{\prime}}, \bar{B}, \bar{C}, \overline{D^{`}}\right)$, and order n-l belong to $H_{\infty}^{-}(r)$. There should be exactly r stable poles and n-r-1 unstable poles. We prove below that $\mathrm{E}(\mathrm{s})=\mathrm{G}(\mathrm{s})-\mathrm{Q}(\mathrm{s})$. Fulfilled the condition

$$
E(s) \sim E(s)=\sigma_{r+1}^{2} I
$$

As follows the $E(s)=E(-s)^{T}$ and hence the all solution of linear roust control with linear fractional transformation as following lemma.

\section{NUMERICAL EXAMPLE}

Example1. Fractional order model of heating furnace [1] be. $G_{1}(s)=\frac{1}{14994 s^{1.31}+6009.5 s^{0.97}+1.69}$

First we have to approximate this model. Using MATLAB toolbox equation 4.32 have to be approximated.

For approximating heat furnace mathematical model given by equation 4.32, we use Oustaloup's method. The approximated integer order model of equation (32) have been given by equation 4.33 .

$$
R_{1} \quad \begin{gathered}
3.838 \times 10^{-6} s^{14}+0.05644 s^{13}+205.3 s^{12}+1.721 \times 10^{5} s^{11}+4.211 \times 10^{7} s^{10} \\
+2.503 \times 10^{9} s^{9}+4.387 \times 10^{10} s^{8}+1.874 \times 10^{11} s^{7}+2.364 \times 10^{11} s^{6}+ \\
7.265 \times 10^{10} s^{5}+6.587 \times 10^{9} s^{4}+1.45 \times 10^{8} s^{3}+9.323 \times 10^{5} s^{2}+1381 s \\
+\quad \begin{array}{c}
+0.5059 \\
s^{15}+1.246 \times 10^{4} s^{14}+2.827 \times 10^{7} s^{13}+1.762 \times 10^{10} s^{12}+2.719 \times 10^{12} s^{11}
\end{array} \\
+1.216 \times 10^{14} s^{10}+1.4 \times 10^{15} s^{9}+4.681 \times 10^{15} s^{8}+4.184 \times 10^{15} s^{7} \\
+1.076 \times 10^{15} s^{6}+7.729 \times 10^{13} s^{5}+1.555 \times 10^{12} s^{4} \\
9.074 \times 10^{9} s^{3}+1.479 \times 10^{7} s^{2}+7692 s \\
+1.256
\end{gathered}
$$

Validation of Approximated Model (Equation 33)

- The approximated integer order model of fractional order system represented by equation 33

- For validating this approximated model represented by equation 33, we have to compare the time response of fractional system $\left(\mathrm{G}_{1}\right)$ of equation 4.32 and approximated integer order model $\left(\mathrm{R}_{1}\right)$ of equation 33 .

- For validation, Step and Impulse response of $\mathrm{G}_{1}$ and $\mathrm{R}_{1}$ are plotted.

- If the nature of time response of the fractional order system and approximated system are identical, hence approximated model will be validated.

Figure 1.1 representing step response of equation (32). The step response plot of $\mathrm{G}_{1}$ will attain steady state value. Thus fractional order system seems to be stable .For plotting step response of fractional order system represented by equation (32) MATLAB tool have been used. 
Vol. 5, Issue 5, May 2017
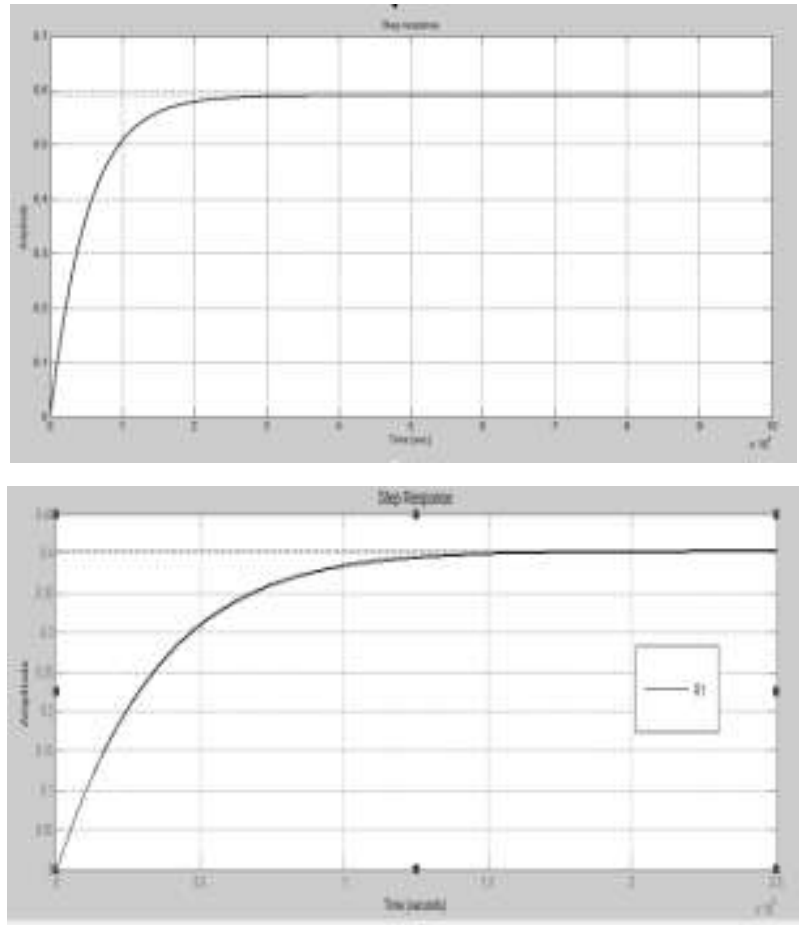

Figure 2 representing step response of equation( 33). The step response plot of $R_{1}$ will attain steady state value. Thus approximated system seems to be stable .For plotting step response of approximated model of $15^{\text {th }}$ order system represented by equation 33 MATLAB tool have been used.

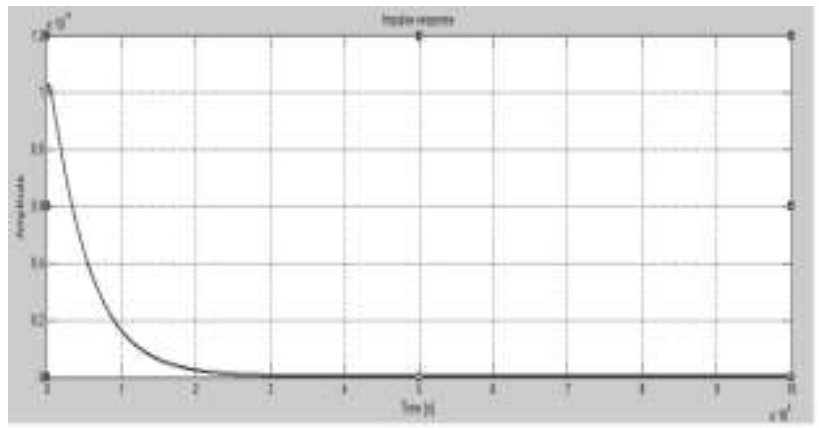

Figure 3 Impulse response of $\mathbf{G}_{1}$

Figure 3 representing impulse response of equation 32. From impulse response of fractional order system it has been found that the fractional order system will survive if any impulsive noise certainly occurred on the system. Thus fractional order system seems to be stable. For plotting impulse response of fractional system represented by equation 32 MATLAB tool have been used.

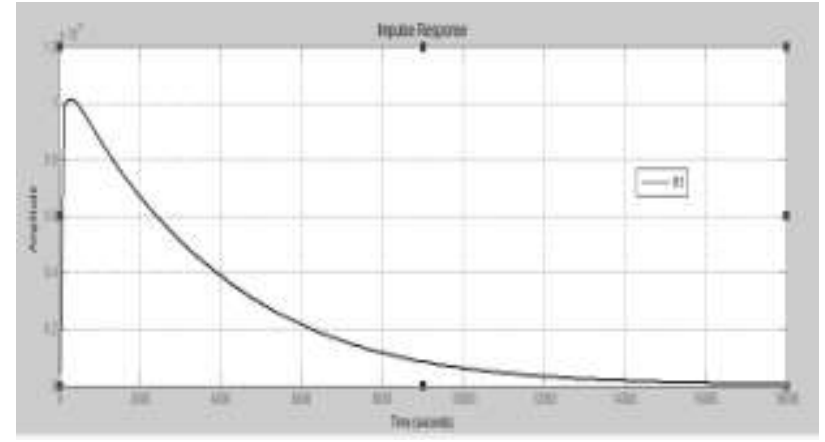

Figure 4 Impulse response of approximated model 
Figure 4 representing impulse response of equation (33). From impulse response of approximated model it has been found that the approximated system will survive if any impulsive noise certainly occurred on the system. Thus approximated system seems to be stable. For plotting impulse response of approximated model represented by equation (33) MATLAB tool have been used.

From figure (1 ) \& (2) it will be found that step response of both the fractional order system and approximated model of fractional system are identical in nature. Hence it will be sure that both the systems are identical in nature.

From figure (3) \& (4) it will be found that impulse response of both the fractional order system and approximated model of fractional system are identical in nature. Hence it will be sure that both the systems are identical in nature.

\section{Model Order Reduction of Approximated Integer Order Model.}

The need of model order reduction at this step arises because the approximated model will be of $15^{\text {th }}$ order and controller of such high order will be very costly and bulky.

- For reducing the order of $\mathrm{R}_{1}$, MATLAB tool has been used.

- The method used for order reduction is Hankel-norm approximation.

- For MOR of approximated model represented by equation (33), in build MATLAB command has been used.

- Now the reduced $5^{\text {th }}$ order model of $\mathrm{R}_{1}$ has been calculated as:

$$
\begin{aligned}
& 4.94 \times 10^{-5} s^{4}+1.083 \times 10^{-5} s^{3}+9.919 \times 10^{-8} s^{2} \\
& +1.472 \times 10^{-10} s+5.422 \times 10^{-14} \\
& R_{2}=\frac{s^{5}+0.1227 s^{4}+0.0009547 s^{3}+1.577 \times 10^{-6} s^{2}+}{8.225 \times 10^{-10} s+1.346 \times 10-13} \\
& 8.225 \times 10^{-10} s+1.346 \times 10^{-13}
\end{aligned}
$$

\section{Validation of $5^{\text {th }}$ Order Reduced Model $\mathbf{R}_{2}$ (Equation 34)}

For validating reduced order model represented by equation (34) of $15^{\text {th }}$ order system represented by equation (33) time response plots has been drawn. By the comparison of nature of time response it should be validated that reduced order model represented by equation (34) have behavioral properties of approximated model represented by equation (33) and hence properties of fraction order system too.

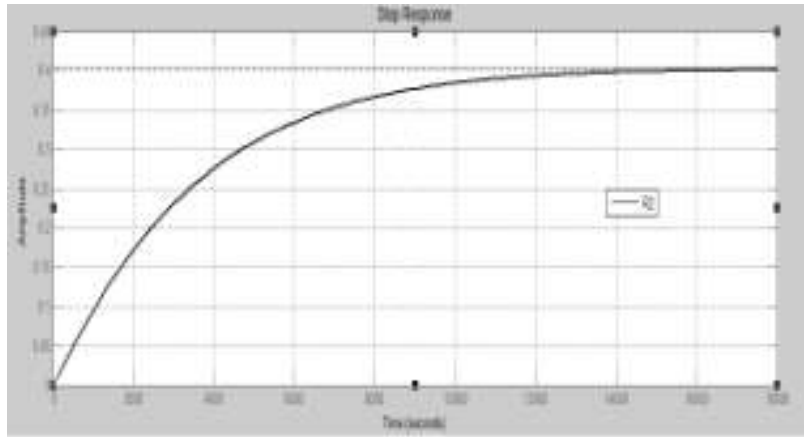

Figure 5 Step response of R2

Figure 5 representing step response of equation (34). The step response plot of $\mathrm{R}_{2}$ will attain steady state value. Thus reduced $5^{\text {th }}$ order system seems to be stable .For plotting step response of reduced order model of $5^{\text {th }}$ order system represented by equation (34) MATLAB tool have been used.

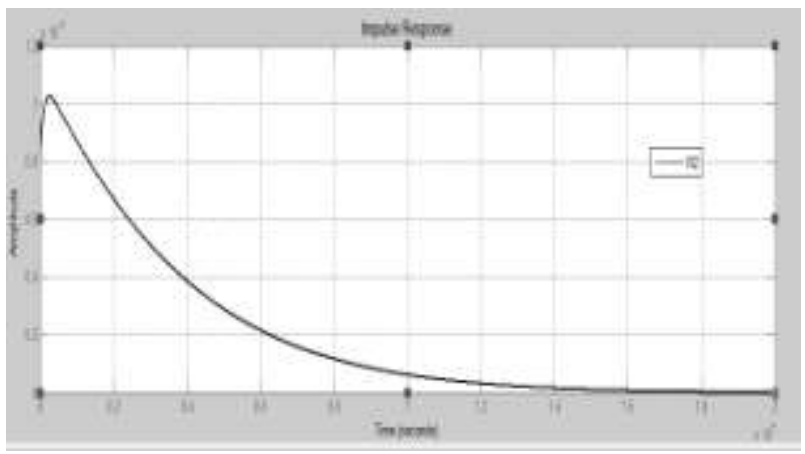

Figure 6 Impulse response of R2 


\section{IJIREEICE \\ International Journal of Innovative Research in Electrical, Electronics, Instrumentation and Control Engineering \\ ISO 3297:2007 Certified \\ Vol. 5, Issue 5, May 2017}

Figure 6 representing impulse response of equation (34). From impulse response of reduced order model it has been found that the reduced $5^{\text {th }}$ order system will survive if any impulsive noise certainly occurred on the system. Thus reduced $5^{\text {th }}$ order system seems to be stable. For plotting impulse response of reduced order model represented by equation (34) MATLAB tool have been used.

From figure (2) \& (5) it will be found that step response of both the approximated model of $15^{\text {th }}$ order and reduced $5^{\text {th }}$ order model are identical in nature. Hence it will be sure that both the systems are identical in nature.

From figure $4 \& 6$ it will be found that impulse response of both the approximated model of fractional system and reduced order model of approximated model are identical in nature. Hence it will be sure that both the systems are identical in nature.

Hence reduced order model represented by equation (34) posses behavioral properties of approximated model represented by equation (33).

Example2. Fractional order model of Permanent magnet synchronous motor velocity servo system [4] represented by:

$G_{m}(s)=\frac{6.8251}{s^{1.7452}+222.222 s^{0.9251}+37665}$

- First we have to approximate this model.

- Using MATLAB toolbox equation (35) have to be approximated.

For approximating PMSM velocity servosystem mathematical model given by equation (35), Oustaloup's method has been used. The approximated integer order model of equation (35) have been given by equation (36).

$$
\begin{gathered}
0.007134 s^{14}+124.6 s^{13}+6.109 \times 10^{5} s^{12}+6.328 \times 10^{8} s^{11}+2.089 \times 10^{11} s^{10}+1.538 \times 10^{13} s^{9}+ \\
3.636 \times 10^{14} s^{8}+1.925 \times 10^{15} s^{7}+3.274 \times 10^{15} s^{6}+1.274 \times 10^{15} s^{5}+ \\
1.525 \times 10^{14} s^{4}+4.16 \times 10^{12} s^{3}+3.616 \times 10^{10} s^{2}+6.64 \times 10^{7}+ \\
3.424 \times 10^{4}
\end{gathered}
$$

$$
\begin{aligned}
& R_{1 m}=\frac{s^{15}+1.205 \times 10^{4} s^{14}+2.773 \times 10^{7} s^{13}+2.377 \times 10^{10} s^{12}+8.918 \times 10^{12} s^{11}}{1.96} \\
& +1.558 \times 10^{15} s^{10}+9.486 \times 10^{16} s^{9}+2.065 \times 10^{18} s^{8} \\
& +1.073 \times 10^{19} s^{7}+1.811 \times 10^{19} s^{6}+6.886 \times 10^{18} s^{5}+8.417 \times 10^{17} s^{4} \\
& +2.296 \times 10^{16} s^{3}+1.996 \times 10^{14} s^{2}+3.666 \times 10^{11} s+1.889 \times 10^{8}
\end{aligned}
$$

\section{Validation of Approximated Model (Equation 36)}

The approximated integer order model of fractional order system has been represented by equation (36).

For validating this approximated model represented by equation (36), we have to compare the time response of fractional system $\left(\mathrm{G}_{\mathrm{m}}\right)$ of equation (35) and approximated integer order model $\left(\mathrm{R}_{1 \mathrm{~m}}\right)$ of equation $(36)$.

For validation, Step and Impulse response of $\mathrm{G}_{\mathrm{m}}$ and $\mathrm{R}_{1 \mathrm{~m}}$ are plotted.

If the nature of time response of the fractional order system and approximated system are identical, hence approximated model will be validated.

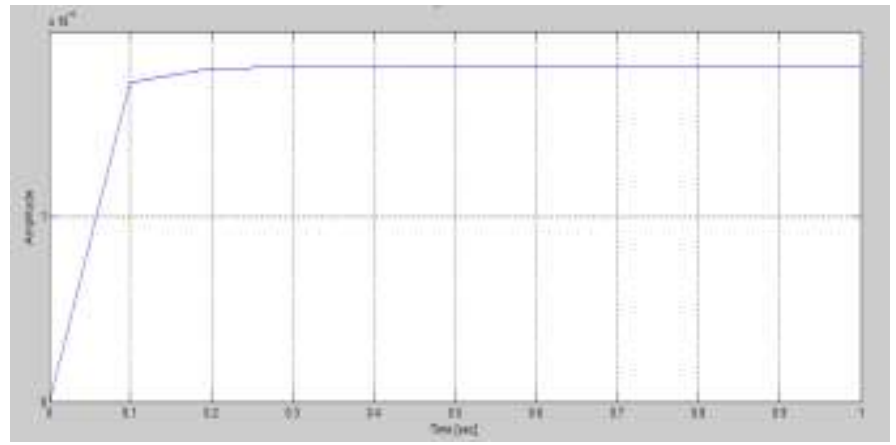

Figure 8 Step response of Gm

Figure 8 representing step response of equation (35). The step response plot of $\mathrm{G}_{\mathrm{m}}$ will attain steady state value. Thus fractional order system seems to be stable .For plotting step response of fractional order system represented by equation (35) MATLAB tool have been used. 
Vol. 5, Issue 5, May 2017

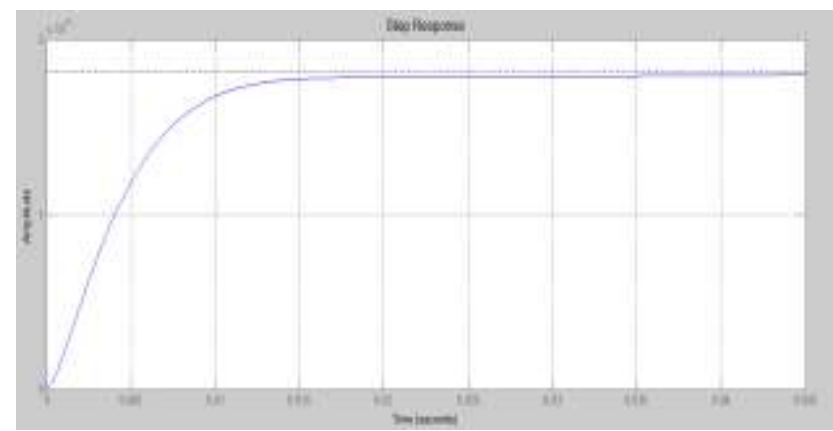

Figure 9 Step response of $\boldsymbol{R}_{\mathbf{1 m}}$

Figure 9 representing step response of equation (36). The step response plot of $R_{1 m}$ will attain steady state value. Thus approximated system seems to be stable. For plotting step response of approximated model of $15^{\text {th }}$ order system represented by equation (36) MATLAB tool have been used.

From figure. 8 \& 9 it will be found that step response of both the fractional system represented by equation (35) and approximated model of $15^{\text {th }}$ order model are identical in nature. Hence it will be sure that both the systems are identical in nature.

Model Order Reduction of Approximated Integer Order Model (Equation 36)

The need of model order reduction at this step arises because the approximated model will be of $15^{\text {th }}$ order and controller of such high order will be very costly and bulky.

- For reducing the order of $\mathrm{R}_{1 \mathrm{~m}}$, MATLAB tool has been used.

- The method used for order reduction is Hankel-norm approximation.

- For MOR of approximated model represented by equation (36), in build MATLAB command has been used.

- Now the reduced $5^{\text {th }}$ order model of $\mathrm{R}_{1}$ has been calculated as:

$R_{2 m}=\frac{0.006687 s^{4}+54.52 s^{3}+2.689 \times 10^{4} s^{2}+1.245 \times 10^{6} s+3.091 \times 10^{6}}{s^{5}+2040 s^{4}+9.757 \times 10^{9} s^{3}+1.834 \times 10^{8} s^{2}+6.977 \times 10^{9} s}$
$+1.707 \times 10^{10}$

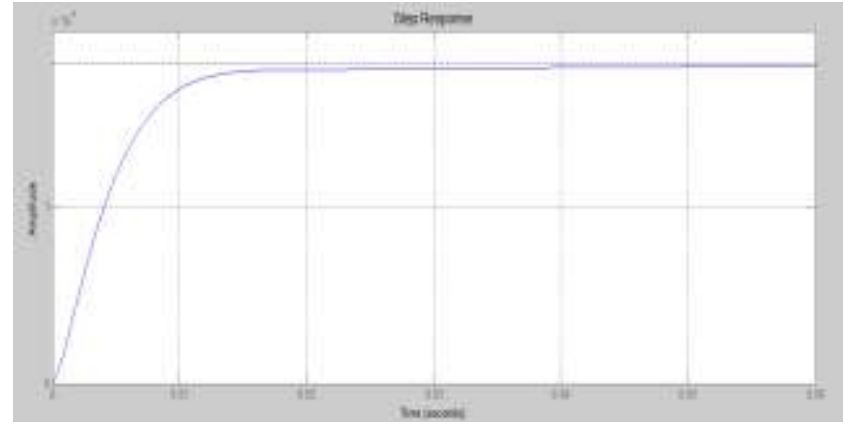

Figure 10 Step response of $\mathrm{R}_{2 \mathrm{~m}}$

Figure 10 representing step response of equation (37). The step response plot of $R_{2 m}$ will attain steady state value. Thus reduced $5^{\text {th }}$ order system seems to be stable .For plotting step response of reduced $5^{\text {th }}$ order system represented by equation (37) MATLAB tool have been used.

From figure $9 \& 10$ it will be found that step response of both the approximated model of $15^{\text {th }}$ order and reduced $5^{\text {th }}$ order model are identical in nature. Hence it will be sure that both the systems are identical in nature. Hence reduced order model represented by equation (36) posses behavioral properties of approximated model represented by equation(37).

\section{DESIGN OF PID CONTROLLE R FOR FRACTIONAL SYSTEM}

We discuss the fractional- order controllers used in the FOMCON toolbox, namely the fractional PID controller, our main focus will be on the fractional PID controller due to its importance in the industry [3].

\section{$P I^{\lambda} D^{\mu}$ Controller Design, Tuning and Optimization}

The non integer order PID controller was first introduced by Podlubny in [1]. The generalized format of non integer order controller will be $\mathrm{PI}^{\lambda} D^{\mu} . \mu \lambda$ 
Vol. 5, Issue 5, May 2017

Where $\lambda$ will be the order of integrator and $\mu$ will be order of differentiator.

Recent researches show that the non integer order PID outperforms of conventional PID controller [3].

The fractional PID controller transfer function has the following form

$$
G_{c}(s)=K_{p}^{\prime}+\frac{K_{i}^{\prime}}{s^{\lambda}}+K_{d}^{\prime} s^{\mu} \quad(\lambda, \mu>0)
$$

When the values of $\mu$ and $\lambda$ are 1 the result is the conventional integer order PID controller. With more degree of freedom in tuning of controller, the 4-point PID design tool can now be seen as a PID controller. The fractional-order PID design tool can be accessed from the GUI by tools fractional PID design or by the fpid command. It allows to design a $P I^{\lambda} D^{\mu}$ controller for a typical negative feedback unity system shown in Figureure. There are several approached for fractional PID design which depend on the plant to be controlled. If the plant is given by an integer order model, then classical tuning procedures could be employed to obtain integer order parameters. Fractional PID orders can then be tune $\mathrm{d}$ to achieve enhanced performance.

- Plant model and fractional PID approximation type. Only Oustaloup's filter type simulations are used mainly due to processing speed.

- Possibility to constrain every tuned parameter, except for the lower bound of the exponents which is fixed

- Possibility to tune all parameters, fix gain or fix fractional exponents.

- Some control over control system performance specifications.

\section{PID Controller Design for Heating Furnace [1]}

Designing controller for fractional order system has been very complicated task. Under this heading reduced order PID controller for reduced $5^{\text {th }}$ order model has been designed. Than this reduced order controller has been applied on original fractional order model of heat furnace. For designing PID controller MATLAB tool has been used.

The tuned PID controller in parallel form will be given as:

$$
C=\frac{s^{2}+1.4388 s+0.0012256}{s}
$$

Applying this PID controller given in equation (7) on fractional order system given in equation (32).

The transfer function of plant (Controller + Fractional system) has been evaluated as:

$$
P=\frac{s^{2}+1.4388 s+0.0012256}{14994 s^{2.31}+s^{2}+6009.5 s^{1.97}+3.1288 s+0.0012256}
$$

Time response of complete plant with controller given in figure 1 and 2

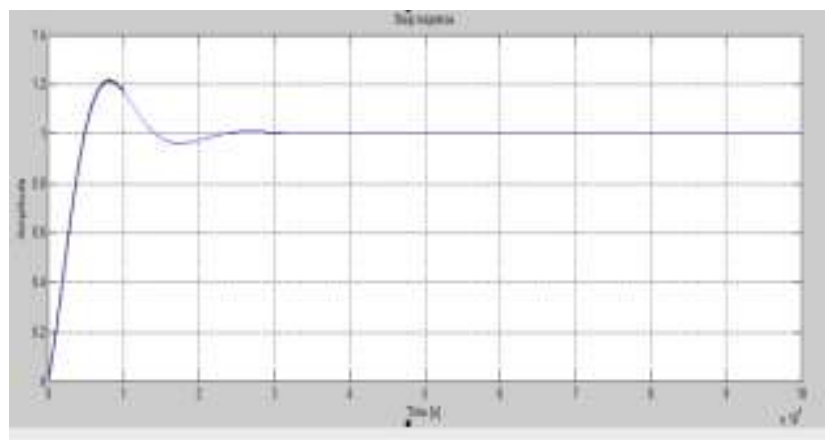

Figure 11 Time response of plant

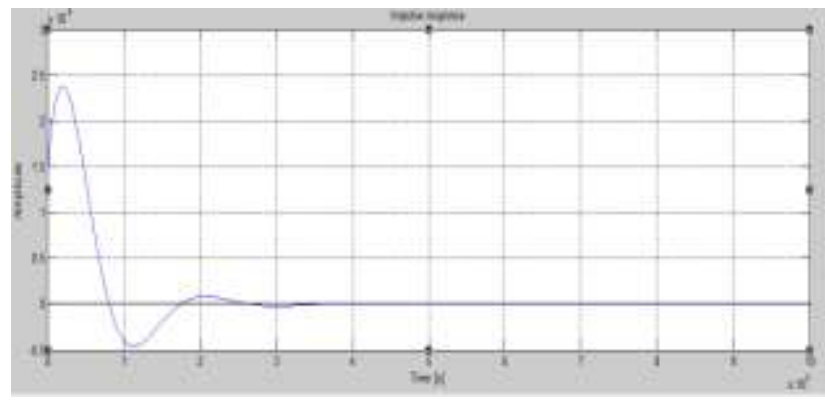

Figure 12 Impulse response of plant 


\section{IJIREEICE \\ Vol. 5, Issue 5, May 2017}

Figure 11 showing step response of heat furnace with controller. Controller improves step response of plant. Impulse response of plant has been plotted. In Figure 12 impulse response of plant given by equation shown. From figure 12 it has been clear that plant sustain if any impulsive signal affect the plant.

\section{PID Controller Design for PMSM Velocity Servo System [4]}

Designing controller for fractional order system has been very complicated task. Under this heading reduced order PID controller for reduced $5^{\text {th }}$ order model has been designed. Than this reduced order controller has been applied on original fractional order model of PMSM velocity servo system. For designing PID controller MATLAB tool has been used.

The tuned PID controller in parallel form will be given as:

$$
C_{1 m}=\frac{9746.7(s+324)}{s}
$$

Applying this PID controller given in equation on fractional order system given in equation (35).

The transfer function of plant (Controller + Fractional system) has been evaluated as:

$$
C_{p m}=\frac{6.8251 s^{2}+66522 s+7}{s^{2.7452}+6.825 s^{2}+222.22 s^{1.9251+7}}
$$

Time response of complete plant with controller given in figure 13 and 14.

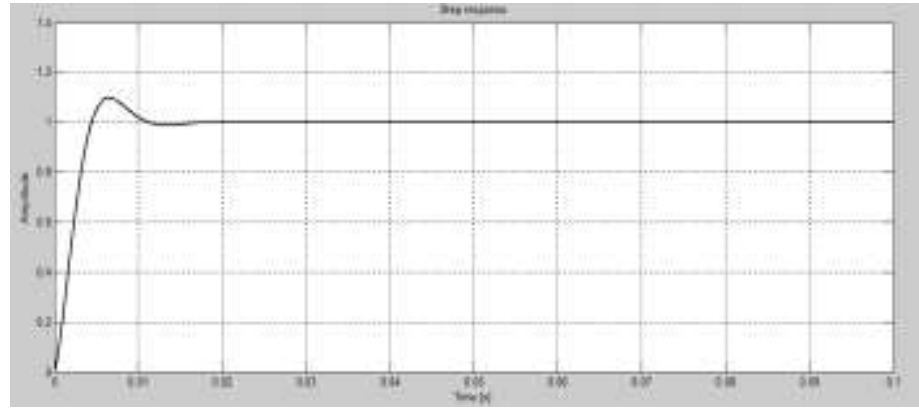

Figure 13 Plant step response

Figure 11 showing step response of PMSM velocity servo system with controller. Controller improves step response of plant.

\section{CONCLUSION}

Mathematical model of SMES velocity servo system and heating furnace are taken for performing the approximation method. Both the fractional order systems are successfully approximated by using the Ostaloop's approximation. The resultant integer order systems are both $15^{\text {th }}$ respectively. These approximated systems are reduced by using the Hankel-norms approximation techniques. Reduced order systems are both $5^{\text {th }}$ order. PID controller for these reduced order systems are successfully constructed and tuned by MATLAB tool. Tuned PID controllers are successfully applied to original fractional order system. The settling time of both the systems are reduced by $0.04 \& 0.25$ respectively.

\section{REFERENCES}

[1] Chunna Zhao and Dingyu Xue, "A fractional order PID Tuning Algorithm for a class of fractional order plants," Proceeding of the IEEE international conference on mechatronics \& automation Niagara falls, Canada, July2005.

[2] Oustaloup, F. Levron, B. Mathieu, and F. M. Nanot, "Frequency-band complex non-integerdifferentiator: characterization and synthesis," vol. 47, no. 1 , pp. 25-39, 2000.

[3] Mohammad Reza Faieghi and Abbas Nemati, “ ON fractional order PID design,” Islamic Azad University, Miyaneh, Iran.

[4] Wei Yu, Ying Luo, YouGuo Pi, "Fractional order modeling and control for permanent synchronoes motor velocity servo system," Mechatronics(2013)

[5] D. Y. Xue, C.N. Zhao and Y.Q. Chen, "Fractional order PID Control of a DC-motor with elastic shafts: a case study", Proc. Of the 2006 American Control Conference, MN, USA, June 2006. 